\title{
Phenotypic Diversity of Organic Acids, Sugars and Volatile Compounds Associated with Subpopulations in Japanese Apricot (Prunus mume) Cultivars
}

\author{
Takuya Morimoto $^{1 *}$, Yuya Murai $^{2}$, Rio Yamauchi², Yuto Kitamura ${ }^{3}$, Koji Numaguchi ${ }^{4}$ \\ and Akihiro Itai ${ }^{1}$
}

\author{
${ }^{1}$ Graduate school of Life and Environmental Sciences, Kyoto Prefectural University, Kyoto 606-8502, Japan \\ ${ }^{2}$ Faculty of Life and Environmental Sciences, Kyoto Prefectural University, Kyoto 606-8502, Japan \\ ${ }^{3}$ Faculty of Agriculture, Setsunan University, Hirakata 573-0101, Japan \\ ${ }^{4}$ Japanese Apricot Laboratory, Wakayama Fruit Experiment Station, Minabe, Wakayama 645-0021, Japan
}

Japanese apricot (Prunus mume) cultivars have been classified into several subpopulations, such as fruiting, fruiting-small, and ornamental, based on a variety of morphological traits and human preference. A recent genome-wide analysis indicated that these subpopulations show some genetic differentiation, but the fruit traits remain to be investigated. Therefore, we investigated phenotypic diversity of several fruit traits, such as sugar, organic acid, and volatile compound contents and compositions, in a variety of cultivars of Japanese apricot (P. mume), apricot (P. armeniaca) and their interspecific hybrids. We found that Japanese apricot cultivars show diverse phenotypic variation and that some fruit traits appeared to be associated with the differing subpopulations. The fruiting cultivars investigated appear to have higher contents of sugars and favorable volatile compounds such as lactones and esters. We also found that 'Joshuhaku', a local cultivar in Kyoto Prefecture, has desirable fruit traits including large fruit size, high contents of organic acid and favorable volatile compounds. Moreover, interspecific hybridization was found to have large effects on fruit traits. Our results indicated a wide diversity of fruit traits in Japanese apricot, in which sugars and volatile compounds were associated with fruiting cultivars. These observations may assist with the breeding of new Japanese apricot cultivars.

Key Words: aroma, fruit quality, gamma-decalactone, genetic diversity, Rosaceae.

\section{Introduction}

Japanese apricot (Prunus mume) belongs to the genus Prunus in the Rosaceae, which includes economically important fruit crops such as peach (P. persica), almond (P. dulcis), apricot (P. armeniaca), Japanese plum (P. salicina), European plum (P. domestica), and sweet cherry (P. avium). The cultivation of Japanese apricot in Japan is believed to have started approximately 2,000 years ago and was originally for ornamental purposes (Yoshida, 1996a). Since then, hundreds of cultivars have been recorded and cultivated for both their flowers

Received; April 20, 2021. Accepted; July 27, 2021.

First Published Online in J-STAGE on October 5, 2021.

A part of this work was presented at the meeting of the Japanese society for Horticultural Science held in March 2021.

This work was supported by JSPS KAKENHI Grant Number 19K15834 to TM.

* Corresponding author (E-mail: morimoto@kpu.ac.jp). and fruits (Horiuchi, 1996; Yoshida, 1996b). Fruiting cultivars of Japanese apricot have the sixth largest cultivation area among fruit trees in Japan, covering an area of 14,100 ha and producing 71,100 tonnes of fruit in 2020 (Ministry of Agriculture, Forestry and Fisheries, 2020).

In general, Japanese apricot cultivars in Japan can be divided into several subpopulations, including fruiting (F), fruiting-small (FS), ornamental (O), and Taiwanese (T) cultivars (Numaguchi et al., 2019). This classification was originally derived based on a variety of morphological traits and human preference. However, a recent phylogenetic and structural analysis based on genome-wide single-nucleotide polymorphism (SNP) data suggested that these subpopulations also show some genetic differentiation (Numaguchi et al., 2020). Japanese apricot and other species within the subgenus Prunus (Japanese apricot, apricot and plums) are interspecifically cross-compatible and easily form inter- 
specific hybrids (Morimoto et al., 2019). Actually, interspecific introgression from apricot (P. armeniaca) and Japanese plum are frequently detected in the genome of Japanese apricot, indicating interspecific crossing involvement in the establishment of the Japanese apricot subpopulations (Numaguchi et al., 2020).

Japanese apricot fruit are mainly used in processed products, such as pickles, liqueurs, and syrups. The quality of these products is largely affected by the fruit materials used, and the maturity of the fruit can be an important consideration when making processed foods (Tokitomo et al., 2005; Oe et al., 2012). A number of fruit traits show dynamic changes during fruit maturation, including the size, organic acid content, and aroma of the fruit (Kakiuchi et al., 1985; Oe et al., 2012). However, these traits are considered to vary among cultivars according to the genetic structure. For example, fruiting-small (FS) cultivars of Japanese apricot are genetically closely related to each other and bear smallsized fruits (Yaegaki et al., 2003). The mature fruits of Japanese apricot cultivars contain citric acid as a major organic acid, whereas the fruits of interspecific hybrids between Japanese apricot (P. mume) and apricot (P. armeniaca) have a higher malic acid content at maturity (Kakiuchi et al., 1985). However, there has not yet been a comprehensive analysis of the fruit traits across a range of cultivars, despite the fact that characterization of the phenotypic diversity associated with the genetic structure would help establish an efficient breeding program by providing important information in a range of areas, such as cultivar selection for crosses and the development of marker-assisted selection.

At the present, 'Nanko' and 'Shirokaga' are the leading cultivars in Japan for fruit production, accounting for $36.2 \%$ and $9.8 \%$, respectively, of total cultivation area (Ministry of Agriculture, Forestry and Fisheries, 2020, 2021). On the other hand, minor cultivars are still cultivated locally, and may possess useful agronomic traits for production as well as future breeding programs, although research efforts are limited so far.

In the present study, we investigated the fruit traits in a range of Japanese apricot (P. mume) cultivars, apricot $(P$. armeniaca) cultivars, and interspecific hybrid cultivars to characterize phenotypic diversity associated with cultivar difference, subpopulations and interspecific hybridization in Japanese apricot. Our investigation also considered the characterization of a local cultivar, 'Joshuhaku', which is cultivated in Kyoto Prefecture, Japan (Yoshida, 1996b; Ministry of Agriculture, Forestry and Fisheries, 2021), and is known for its large fruit size and favorable fruit aroma.

\section{Materials and Methods}

\section{Plant materials}

A total of 16 Japanese apricot (P. mume) cultivars, 2 apricot (P. armeniaca) cultivars, and 2 interspecific hybrid cultivars arising from crosses between the two species were used in this study (Table 1; Supplemental Table S1). To ensure representation of the current genetic diversity among Japanese apricot cultivars available in Japan, we used a phylogenetic tree that was previously constructed using genome-wide SNP data (Numaguchi et al., 2020). For fruiting (F and FS) cultivars, we mainly selected major cultivars such as 'Nanko' and 'Shirokaga', and recent breeding cultivars such as 'Hachiro', 'Suiko', and 'Toko'. All of the cultivars except 'Joshuhaku' were maintained in the Japanese Apricot Laboratory at the Wakayama Fruit Experimental Station in Wakayama Prefecture, Japan $\left(33.8^{\circ} \mathrm{N}, 135.4^{\circ} \mathrm{E}\right)$, while 'Joshuhaku' was maintained at a private orchard in Joyo city in Kyoto Prefecture $\left(34.8^{\circ} \mathrm{N}, 135.8^{\circ} \mathrm{E}\right)$. All of the trees were managed using commercial practices. The fruit of each cultivar were harvested on trees from May 31 to July 3 (Table 1), following the maturation criterion suitable for harvest, in which a pedicel could be easily detached from the fruit. Harvested fruits were maintained in a cooler box with ice pack to keep the fruit temperature cool during shipping to the laboratory.

\section{Evaluation of fruit traits}

\section{Evaluation of the physical fruit traits and fruit aroma intensity}

Fruit trait evaluation was conducted on the day or next day of fruit harvest. The fruits were assessed 2 hours after return to room temperature condition and evaluated for fruit weight, stone weight, fruit firmness, organic acid content, sugar content, volatile compound content, and fruit aroma intensity. The fruit aroma was evaluated by two panelists (22- and 30-year-old males), who categorized the intensity of the favorable aroma, which is characterized as being sweet and peach-like, into one of four classes: 1: no aroma or traces of an aroma; 2: weak aroma; 3: medium aroma; 4: strong aroma. Fruit weight, stone weight, and fruit firmness measurements were taken from five fruit per cultivar, with fruit firmness being determined in unpeeled fruit using a rheometer (RT-3010D; Rheotech, Tokyo, Japan). The fruit tissues (skin and flesh) from at least 10 fruit per cultivar were then pureed using a food processor and stored at $-80^{\circ} \mathrm{C}$ until use.

\section{Evaluation of the sugar and organic acid contents and compositions}

To determine the sugar and organic acid contents, the puree samples were centrifuged at $8,000 \mathrm{rpm}$ for $10 \mathrm{~min}$ and then filtered through a $0.45-\mu \mathrm{m}$ syringe filter to obtain juice samples. The sucrose, glucose, fructose, and sorbitol contents of each sample were then determined by adding $20 \mu \mathrm{L}$ of erythritol $(2 \mathrm{mg} / \mathrm{mL})$ as an internal standard to $20 \mu \mathrm{L}$ of the juice sample, diluting the mixture to $1 \mathrm{~mL}$ with ultrapure water, and conducting high-performance liquid chromatography (HPLC) using a PU7714 HLPC system (GL Science Inc., 
Table 1. Plant materials used in this study.

\begin{tabular}{|c|c|c|c|c|}
\hline Species & Name & Group $^{z}$ & Origin & Harvest date \\
\hline \multirow[t]{16}{*}{ P. mume } & Hachiro & $\mathrm{F}$ & Japan $^{\mathrm{y}}$ & 18th Jun \\
\hline & Jizo & $\mathrm{F}$ & Japan & 18th Jun \\
\hline & Joshuhaku & $\mathrm{F}$ & Japan & 28th Jun \\
\hline & Kairyo-uchida & $\mathrm{F}$ & Japan & 31th May \\
\hline & Kensaki & $\mathrm{F}$ & Japan & 13th Jun v \\
\hline & Nanko & $\mathrm{F}$ & Japan & 24th Jun \\
\hline & Oushuku & $\mathrm{F}$ & Japan & 18th Jun \\
\hline & Shirokaga & $\mathrm{F}$ & Japan & 18th Jun \\
\hline & Suiko & $\mathrm{F}$ & $\operatorname{Japan}^{\mathrm{x}}$ & 18th Jun \\
\hline & Toko & $\mathrm{F}$ & Japan $^{\mathrm{w}}$ & 18th Jun \\
\hline & Hakuo & FS & Japan & 31th May \\
\hline & Orihime & FS & Japan & 31th May \\
\hline & Ellching & $\mathrm{T}$ & Taiwan & 3 th Jul $^{\mathrm{v}}$ \\
\hline & Chugoku-ume & $\mathrm{O}$ & Japan & 13th Junv \\
\hline & Kinko & $\mathrm{O}$ & Japan & 18th Jun \\
\hline & Suishin-bai & $\mathrm{O}$ & Japan & 18th Jun \\
\hline \multirow[t]{2}{*}{$P$. mume $\times P$. armeniaca } & Bungo & $\mathrm{AM}$ & Japan & 18th Jun \\
\hline & Seiyo-bai & $\mathrm{AM}$ & Japan & 18th Jun \\
\hline \multirow[t]{2}{*}{ P. armeniaca } & Harcot & A & Canada & 18th Jun \\
\hline & Heiwa & A & Japan & 13th Jun ${ }^{v}$ \\
\hline \multicolumn{5}{|c|}{$\begin{array}{l}\text { According to the report by Hayashi et al. (2008) ar } \\
\text { Taiwanese, O: ornamental, AM: interspecific hybric } \\
\text { Yamaguchi et al. (2002). } \\
{ }^{\text {W }} \text { Yaegaki et al. (2014). } \\
\text { Fegoro et al. (2007). }\end{array}$} \\
\hline
\end{tabular}

Tokyo, Japan) equipped with an InertSphere Sugar-1 column (4.6 $\mathrm{mm}$ inner diameter $\times 150 \mathrm{~mm}$; particle size, $5 \mu \mathrm{m}$; GL Science). Elution was carried out at room temperature at a flow rate of $1 \mathrm{~mL} / \mathrm{min}$ using $0.4 \%(\mathrm{v} / \mathrm{v}) \mathrm{NaOH}$ as a solvent and was monitored by an ED723 electrochemical detector (GL Science).

The citric acid, malic acid, and tartaric acid contents of each sample were determined by adding $6.25 \mathrm{~mL}$ of maleic acid $(1 \mathrm{mg} / \mathrm{mL})$ as an internal standard to $250 \mu \mathrm{L}$ of the juice sample, diluting the mixture to $50 \mathrm{~mL}$ with ultrapure water, and conducting HPLC with an LC-10AT system (GL Science) equipped with a COSMOSIL $5 \mathrm{C}_{18}$ packed column $(4.6 \mathrm{~mm}$ inner diameter $\times 250 \mathrm{~mm}$; particle size, $5 \mu \mathrm{m}$; Nacalai Tesque Inc., Kyoto, Japan). Elution was carried out at room temperature at a flow rate of $1 \mathrm{~mL} / \mathrm{min}$ using $20 \mathrm{mmol} / \mathrm{L}$ phosphate buffer ( $\mathrm{pH}$ 7.0) as a solvent and was monitored by an SPD-10A photodiode array detector (Shimadzu Corp., Kyoto, Japan) at a wavelength of $254 \mathrm{~nm}$.

For both analyses, three replicates of each sample were analyzed. The resulting fraction peaks were determined with the chromato-PRO program (RTC Co., Ltd., Tokyo, Japan) and were used to determine the sugar and organic acid contents based on standard curves constructed with diluted solutions.

\section{Evaluation of the volatile compound contents and compositions}

Volatile compounds were detected using the stir bar sorptive extraction method, which allows a larger amount of sorptive extraction phase to be used, resulting in extremely high sensitivities (Baltussen et al., 1999). The volatile compound content of each sample was determined by placing $10 \mathrm{~g}$ of puree sample and $12 \mathrm{mg} / \mathrm{L}$ of cyclohexanol as an internal standard in a $30-\mathrm{mL}$ headspace vial and then sealing the vial with a septum and aluminum cap. Volatile compounds were then extracted by immersing a Twister ${ }^{\circledR}$ (Gerstel K. K., Tokyo, Japan) in the sample mixture in the vial and leaving the mixture at room temperature for $5 \mathrm{~h}$.

Thermal desorption from the Twister was carried out in a Thermal Desorption Unit (TDU; Gerstel) programmed to increase from $70^{\circ} \mathrm{C}$ (held for $0 \mathrm{~min}$ ) to $250^{\circ} \mathrm{C}$ (held for $3 \mathrm{~min}$ ) at a rate of $720^{\circ} \mathrm{C} \cdot \mathrm{min}^{-1}$ in a splitless mode. The desorbed substances from the TDU were then cryo-focused at $-120^{\circ} \mathrm{C}$ using liquid nitrogen in a programmable temperature-vaporization inlet (CIS4; Gerstel) programmed to increase from $-120^{\circ} \mathrm{C}$ (held for $0 \mathrm{~min}$ ) to $250^{\circ} \mathrm{C}$ (held for $15 \mathrm{~min}$ ) at a rate of $720^{\circ} \mathrm{C} \cdot \mathrm{min}^{-1}$ in a splitless mode. Separation of the substance was performed with an Agilent 7890 gas chromatograph coupled to a 5975C mass spectrometer 
(Agilent Technologies Inc., CA, USA) equipped with a DB-WAX capillary column $(30 \mathrm{~m}$ length $\times 0.25 \mathrm{~mm}$ internal diameter; film thickness, $0.25 \mu \mathrm{m}$; Agilent Technologies) using a 10:1 split ratio with helium carrier gas $\left(1 \mathrm{~mL} \cdot \mathrm{min}^{-1}\right)$. The inlet temperature was set at $250^{\circ} \mathrm{C}$, and the oven temperature was programmed to increase from $40^{\circ} \mathrm{C}$ (held for $2 \mathrm{~min}$ ) to $220^{\circ} \mathrm{C}$ (held for $13 \mathrm{~min}$ ) at a rate of $4^{\circ} \mathrm{C} \cdot \mathrm{min}^{-1}$. The mass detector operated in electron impact mode at $70 \mathrm{eV}$ in the range of $35-500 \mathrm{~m} / \mathrm{z}$. The volatile compounds were identified by comparing their mass spectra with compounds recorded in the NIST08 mass spectral library. The individual volatile compounds were then quantified based on their peak areas relative to the internal standard.

The total amount of volatile compounds was calculated as the sum of the detected peak areas, which were corrected to the peak area of the internal standard (cyclohexanol). The 10 compounds that accounted for the largest proportion of the total amount of volatile compounds in each cultivar were then selected. The amount of each of the resulting 40 compounds was calculated by dividing the peak area of the compound by that of the internal standard, and the amount of each compound relative to the total amount of volatile compounds was also calculated. The resulting data were analyzed by principal component analysis (PCA) using the 'prcomp' functions in $\mathrm{R}$.

\section{Results}

\section{Evaluation of fruit traits}

\section{Fruit weight, stone weight, and fruit firmness}

The fruit weight varied greatly among the cultivars used in this study, ranging from $6.5 \pm 0.3 \mathrm{~g}$ in 'Hakuo' to $92.5 \pm 5.8 \mathrm{~g}$ in 'Harcot' (Supplemental Fig. S1A). However, there was no clear difference in fruit weight between the fruiting $(\mathrm{F})$ and ornamental $(\mathrm{O})$ cultivars. The fruit weight of 'Joshuhaku' $(66.8 \pm 1.9 \mathrm{~g})$ was greater than other Japanese apricot cultivars examined, as well as the two interspecific hybrids ('Seiyobai' and 'Bungo') and the apricot cultivar 'Heiwa'. The stone weight varied from $0.51 \pm 0.02 \mathrm{~g}$ in 'Hakuo' to $5.78 \pm$ $0.29 \mathrm{~g}$ in 'Joshuhaku' (Supplemental Fig. S1B). There was a relatively high correlation between fruit weight and stone weight $(r=0.71)$, as previously reported (Yaegaki et al., 2003). The percentage of the stone weight varied from $5.4 \% \pm 0.28 \%$ in 'Kensaki' to $10.1 \% \pm 0.25 \%$ in 'Suishinbai' (Supplemental Fig. S1C). However, the Taiwanese (T) cultivar 'Ellching' was an exception to this, reaching a value of $19.7 \% \pm 3.34 \%$. Fruit firmness varied from $10.6 \pm$ $0.3 \mathrm{~N}$ ('Kairyo-uchida') to $19.6 \pm 0.8 \mathrm{~N}$ ('Suinshinbai'), with 'Joshuhaku' having a value of $11.45 \pm 0.4 \mathrm{~N}$ (Supplemental Fig. S1D).

\section{Sugar and organic acid contents and compositions}

The sugars sucrose, glucose, fructose, and sorbitol were detected in the juice samples extracted from the skin and flesh tissues, and their contents and composi- tions showed large variations among the cultivars and species examined (Fig. 1A, B; Supplemental Table S2). In Japanese apricot, the total sugar content ranged from $5.38 \pm 0.78 \mathrm{mg} \cdot \mathrm{mL}^{-1}$ in 'Suishinbai' to $16.39 \pm$ $0.70 \mathrm{mg} / \mathrm{mL}$ in 'Nanko' and tended to be higher in the fruiting (F) and fruiting-small (FS) cultivars (12.02 \pm $\left.0.85 \mathrm{mg} \cdot \mathrm{mL}^{-1}\right)$ than in the ornamental $(\mathrm{O})$ cultivars $\left(7.80 \pm 1.24 \mathrm{mg} \cdot \mathrm{mL}^{-1}\right)$ (Fig. 1A). In contrast, the apricot cultivars had higher sugar contents than the Japanese apricot cultivars, ranging from $29.02 \pm$ $2.20 \mathrm{mg} \cdot \mathrm{mL}^{-1}$ in 'Heiwa' to $79.23 \pm 3.14 \mathrm{mg} \cdot \mathrm{mL}^{-1}$ in 'Harcot', while the interspecific hybrids showed intermediate values. Among the four sugars, sucrose was detected as a major sugar in all of the cultivars examined and was a determinant of cultivar differences in sugar content and composition, with the sucrose composition ranging from $34.89 \%$ in 'Suishinbai' to $79.42 \%$ in 'Nanko' and being higher in the fruiting (F) cultivars $(62.8 \%)$ than in the fruiting-small (FS) $(48.1 \%)$ and ornamental (O) (42.1\%) cultivars (Fig. 1B).

The organic acids (citric acid, malic acid, and tartaric acid) were identified in the juice samples and quantified. The total content, individual contents and compositions of these organic acids showed variation among the Japanese apricot cultivars and between species examined (Fig. 1C, D; Supplemental Table S3). Japanese apricot cultivars had citric acid as a major organic acid, the content and composition of which showed large differences among the cultivars (Fig. 1D). Thus, the cultivars 'Joshuhaku', 'Nanko', 'Hachiro', and 'Chugoku-ume' had higher citric acid compositions $(83.90 \%-90.39 \%)$, whereas the other cultivars had citric acid compositions of approximately $70 \%$. No clear differences were observed between the Japanese apricot subpopulations. Although the total organic acid content of the Japanese apricot cultivars was higher than that of the apricot cultivars, it was comparable to the interspecific hybrid cultivars, 'Bungo' and 'Seiyo-bai' (Fig. 1C). By contrast, the two interspecific hybrid cultivars had a higher composition of malic acid than most of the Japanese apricot cultivars, suggesting that organic acid composition may be affected by interspecific hybridization.

3. Fruit aroma intensity and volatile compound contents and compositions

In total, 109 compounds were detected across the 20 cultivars examined (data not shown), with the total number of detected compounds per cultivar varying from 15 in 'Heiwa' to 31 in 'Toko'. In particular, a relatively large number of volatile compounds was detected in the fruiting (F) cultivars, such as 'Joshuhaku' (30) and 'Suiko' (29).

Most fruiting (F) cultivars contained large amounts of total volatile compounds and had strong aroma intensities according to the sensory evaluation (e.g., 'Nanko', 'Toko', 'Suiko', 'Kensaki', 'Kairyouchida- 


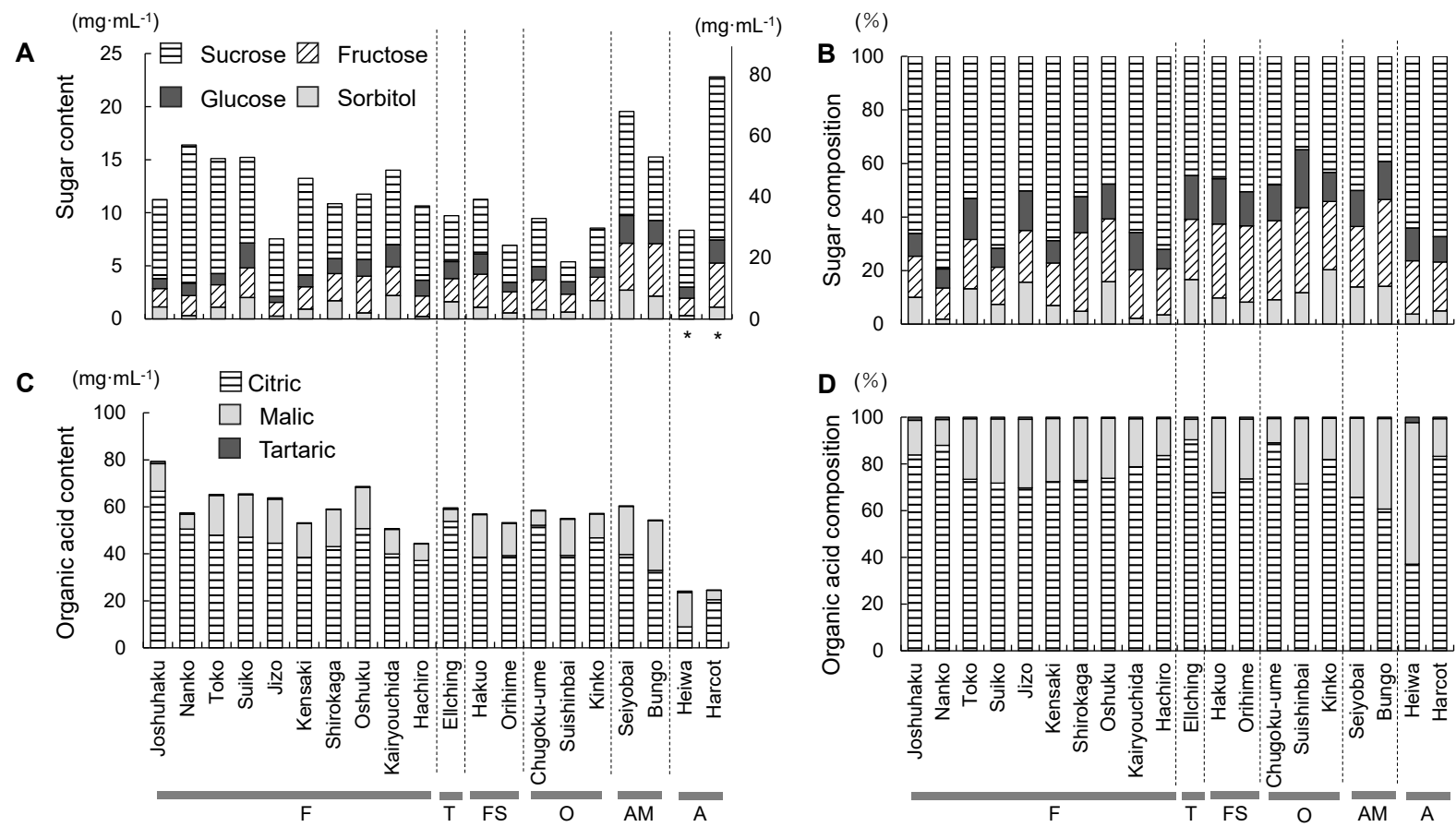

Fig. 1. Differences in the sugar content (A), sugar composition (B), organic acid content (C), and organic acid composition (D) among 20 cultivars of Japanese apricot (Prunus mume), apricot (P. armeniaca), and their interspecific hybrids. F: fruiting; T: Taiwanese; FS: fruiting-small; O: ornamental; AM: interspecific hybrid of Japanese apricot and apricot; A: apricot. * Sugar contents of apricot cultivars are shown on the right $y$-axis.

ume', and 'Hachiro': Fig. 2), and there was a positive correlation between the total volatile compound content and aroma intensity for the 16 Japanese apricot and 2 interspecific hybrid cultivars $(r=0.46, P<0.05$ with Pearson's product-moment correlation). However, some fruiting (F) cultivars, such as 'Joshuhaku' and 'Shirokaga', contained small amounts of volatile compounds but still had strong aroma intensities, while the apricot cultivars contained large amounts of total volatile compounds but had weak aroma intensities. These results suggest that the presence or composition of specific compounds may be responsible for aroma intensity and the overall appeal of a given fruit aroma phenotype.

Selection of the 10 compounds that accounted for the largest proportion of the total volatile compounds in each cultivar resulted in a total of 40 compounds being identified (Supplemental Tables S4 and S5). The amount (calculated as the peak area relative to that of the internal standard) and composition (calculated as the proportion of the total volatile compounds) of each compound was then determined. The sensory aroma intensity (Fig. 2) was positively correlated with the proportions of gamma-decalactone $(r=0.72, P<0.01$ with Pearson's product-moment correlation), butyl hexanoate $(r=0.60, P<0.01)$, butyl butanoate $(r=$ $0.58, P<0.01)$, delta-octalactone $(r=0.55, P<0.05)$, and hexyl hexanoate $(r=0.51, P<0.05)$ in the 20 Japanese apricot (P. mume), apricot (P. armeniaca), and interspecific hybrid cultivars examined, indicating that

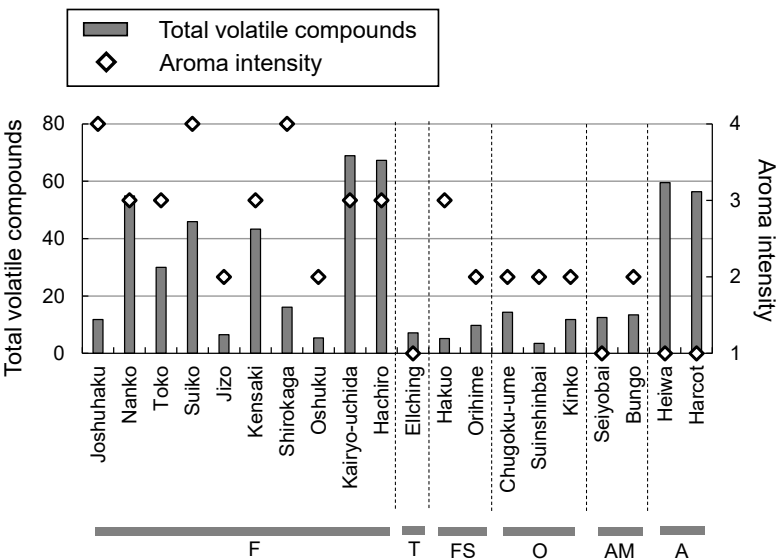

Fig. 2. Differences in the total volatile compound content and sensory aroma intensity among 20 cultivars of Japanese apricot (Prunus mume), apricot (P. armeniaca), and their interspecific hybrids. The total volatile compound content (shown as bars) was determined as the peak area of the total volatile compounds relative to that of the internal standard (cyclohexanol). F: fruiting; T: Taiwanese; FS: fruiting-small; O: ornamental; AM: interspecific hybrid of Japanese apricot and apricot; A: apricot.

higher proportions of these volatiles may be responsible for a favorable fruit aroma. By contrast, none of the correlations between favorable aroma and the amounts of any other compounds were greater than $r=0.50$.

The amounts and compositions of the 40 compounds were also analyzed by PCA to characterize the variability of volatile compounds in the 20 cultivars of 
Japanese apricot (P. mume), apricot (P. armeniaca) and the interspecific hybrid (Fig. 3). In terms of the amount data, the first two principal components (PC1 and $\mathrm{PC} 2$ ) together explained $39.0 \%$ of the total variability among the cultivars, with $\mathrm{PC} 1$ describing $21.3 \%$ of the total variability and mainly differentiating the fruiting $(\mathrm{F})$ cultivars from the cultivars in other subpopulations (FS, $\mathrm{O}, \mathrm{T}, \mathrm{AM}$, and A) (Fig. 3A). The fruiting (F) cultivars plotted on the negative side of PC1 (i.e., 'Suiko', 'Nanko', 'Toko', 'Kairyo-uchida', and 'Hachiro') were determined to have strong aroma intensities in the sen- sory evaluation (Fig. 2), indicating that PC1 is likely to represent a favorable aroma component. Thus, volatile compounds that are negatively correlated with PC1 may be responsible for the favorable fruit aroma (Table 2). Volatile compounds that had a factor loading of less than -0.60 to PC1 mainly included hexanoate esters such as hexyl hexanoate $(-0.73)$, butyl hexanoate $(-0.73)$, and butyl caprylate $(-0.70)$, and lactones such as gamma-decalactone $(-0.72)$. These compounds were mainly detected in the fruiting $(\mathrm{F})$ and fruiting-small (FS) cultivars, while trace or undetectable levels of
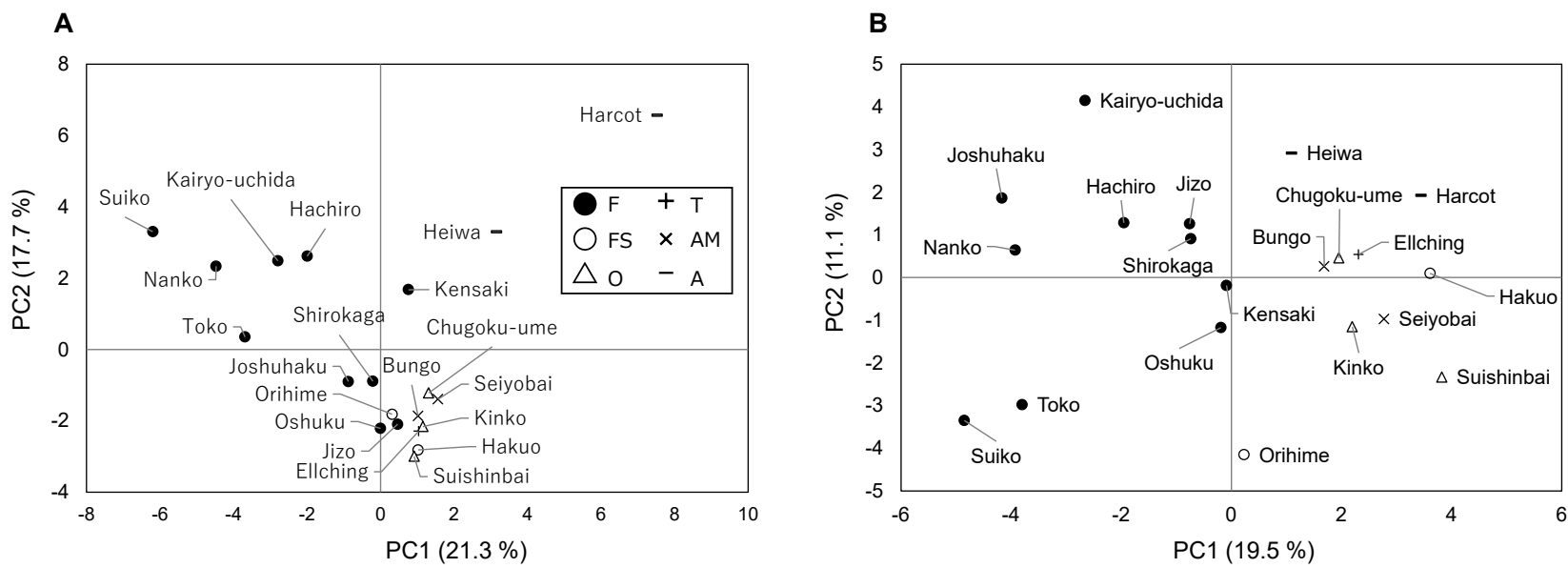

Fig. 3. Principal component analysis of the amount (A) and composition (B) of volatile compounds in 20 cultivars of Japanese apricot (Prunus mume), apricot (P. armeniaca), and their interspecific hybrids. F: fruiting; T: Taiwanese; FS: fruiting-small; O: ornamental; AM: interspecific hybrid of Japanese apricot and apricot; A: apricot.

Table 2. Factor loadings to $\mathrm{PC} 1$ variable.

\begin{tabular}{lc}
\hline \hline \multicolumn{1}{c}{ Compounds } & Loadings \\
\hline Amounts of volatile compounds & \\
Hexyl hexanoate & -0.73 \\
Butyl hexanoate & -0.73 \\
Gamma-decalactone & -0.72 \\
(Z)-3-Hexenyl hexanoate & -0.70 \\
Butyl caprylate & -0.70 \\
2H-Pyran-2-one, tetrahydro-6-propyl (Delta-octalactone) & -0.62 \\
2(4H)-Benzofuranone, 5,6,7,7a-tetrahydro-4,4,7a-trimethyl & 0.67 \\
Dodecanoic acid & 0.65 \\
1-Butanol, 3-methyl acetate & 0.64 \\
1,6.Octadien.3.ol, 3,7-dimethyl & 0.64 \\
2,6-Octadien.1.ol, 3.7.dimethyl acetate & 0.61 \\
1-Hexanol & 0.60 \\
\hline Composition of volatile compounds & \\
gamma-decalactone & -0.82 \\
Butyl hexanoate & -0.77 \\
Hexyl hexanoate & -0.71 \\
Butylcaprylate & -0.69 \\
Butyl butanoate & -0.63 \\
Butyl acetate & -0.62 \\
1,6.Octadien.3.ol, 3,7-dimethyl & 0.61 \\
Tetradecanoicacid & 0.60 \\
\hline
\end{tabular}




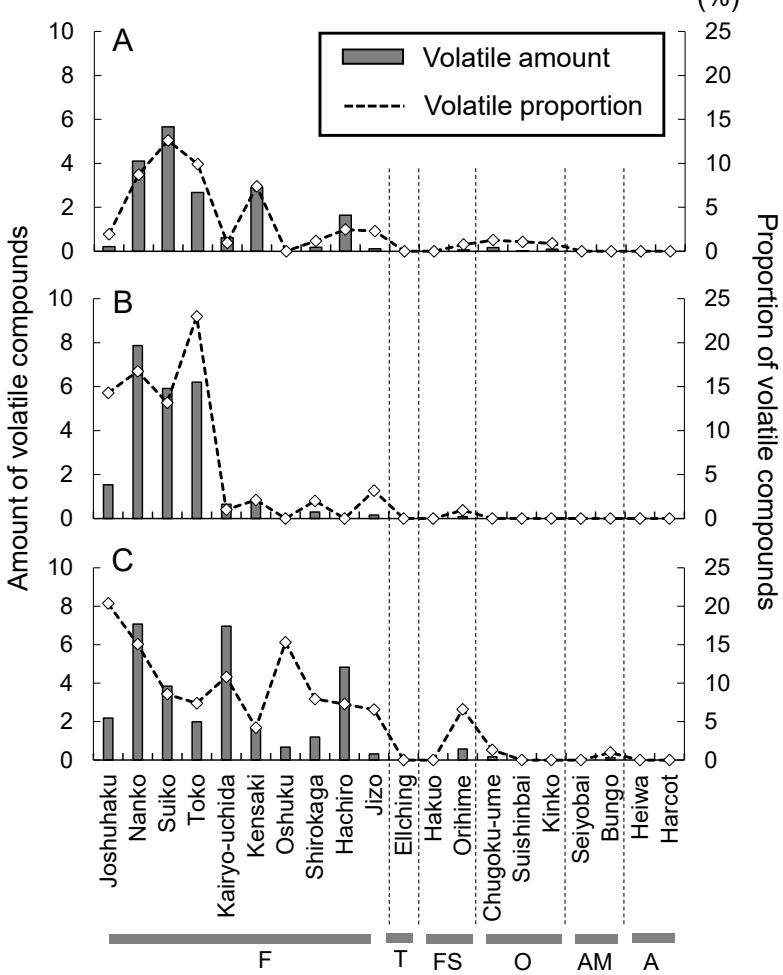

Fig. 4. Associations between the amounts and proportions of hexyl hexanoate (A), butyl hexanoate (B), and gamma-decalactone (C). The amount of each volatile compound (shown as bars) was determined as the peak area of the target volatile compound relative to that of the internal standard (cyclohexanol). The proportion of each volatile compound (shown as dotted lines) was determined as the peak area of the target volatile compound relative to that of the total volatile compounds. F: fruiting; T: Taiwanese; FS: fruiting-small; O: ornamental; AM: interspecific hybrid of Japanese apricot (Prunus mume) and apricot (P. armeniaca); A: apricot.

these compounds were observed in the ornamental $(\mathrm{O})$, Taiwanese (T), interspecific (AM), and apricot (P. armeniaca) (A) cultivars (Fig. 4).

In terms of the composition data, PC1 explained $19.5 \%$ of total variability, clearly differentiating the fruiting (F) cultivars from the cultivars in other subpopulations (Fig. 3B). Some fruiting (F) cultivars showing strong aroma intensities but less total volatile compounds ('Suiko' and 'Joshuhaku') (Fig. 2) plotted on the negative side of PC1. As in the case of the amount data, gamma-decalactone $(-0.82)$, butyl hexanoate $(-0.77)$, and hexyl hexanoate $(-0.71)$ showed lower factor loadings to PC1 (Table 2) and were mainly detected in higher proportions in the fruiting (F) cultivars (Fig. 4). There was a higher correlation between the amount and composition of butyl hexanoate $(r=$ $0.90, P<0.01$ with Pearson's product-moment correlation) and hexyl hexanoate $(r=0.96, P<0.01)$, but weak correlation was observed for gamma-decalactone $(r=0.62, P<0.01)$ (Supplemental Tables S4 and S5). Fruiting (F) cultivars such as 'Joshuhaku' and 'Oshuku' contained lower amounts but higher proportions of gamma-decalactone (Fig. 4).

\section{Discussion}

This study investigated phenotypic variation in the fruit traits of Japanese apricot cultivars with diverse genetic backgrounds by analyzing 16 Japanese apricot cultivars that comprehensively covered the genetic diversity of the species (Numaguchi et al., 2020), including 10 fruiting (F), 2 fruiting-small (FS), 3 ornamental $(\mathrm{O})$, and 1 Taiwanese $(\mathrm{T})$ cultivars, as well as 2 apricot and 2 interspecific hybrid cultivars. We also focused on the local cultivar 'Joshuhaku', which has been cultivated in Kyoto Prefecture for many years and is known for its large fruit and favorable fruit aroma.

'Joshuhaku' had the largest fruit size $(66.8 \mathrm{~g})$ and stone weight $(5.78 \mathrm{~g})$ among the 16 Japanese apricot cultivars investigated (Supplemental Fig. S1A, B). Similarly, previous reports have also indicated that this cultivar produces large fruit (Kakiuchi et al., 1985; Yaegaki et al., 2003). However, the average fruit weight varies among years and locations due to differences in cultivation conditions, such as climate, tree age, and cultural practices (Yaegaki et al., 2014). For example, Yaegaki et al. (2003) reported that 'Joshuhaku' and 'Nanko' had very similar fruit weights $(31.8 \mathrm{~g}$ and $32.8 \mathrm{~g}$, respectively) in 13-15-year-old trees maintained in Ibaraki Prefecture, Japan, whereas these cultivars exhibited a large difference in fruit weight in the present study (Supplemental Fig. S1A). This result can be explained by differences in the cultivation conditions between the cultivars in the present study; 'Joshuhaku' fruit being harvested in Kyoto Prefecture and 'Nanko' fruit being obtained from Wakayama Prefecture. The fruit set of 'Joshuhaku' appeared to be normal in 2019, and a similar difference in fruit size between the two cultivars was also observed in 2020 (data not shown). Therefore, while our investigation indicated that 'Joshuhaku' is likely to have genetic potential to bear large fruit, further research will be needed to confirm its fruit size under different environmental conditions.

The sugar and organic acid contents of the fruit varied greatly among the Japanese apricot cultivars examined as well as between species (Fig. 1A-D). Among the Japanese apricot cultivars, 'Joshuhaku' was shown to have a higher fruit acidity $\left(79.38 \mathrm{mg} \cdot \mathrm{mL}^{-1}\right)$, which mainly resulted from its higher content of citric acid (Fig. 1C). Tokitomo et al. (2005) found that organic acid content and composition of ume liquor is affected by fruit materials. Since organic acid content is an important factor that affects the quality of processed products, this wide diversity of organic acid content among the cultivars examined should be considered when selecting suitable cultivars for fruit use. We also found that the fruiting (F) cultivars had higher sugar contents than cultivars in other subpopulations, mainly due to their higher sucrose contents (Fig. 1A). Sugars 
have received less attention than organic acids in Japanese apricot because of their lower contents in the fruit (5.38-16.39 $\left.\mathrm{mg} \cdot \mathrm{mL}^{-1}\right)$ and lower importance with respect to the quality of processed products. However, our results suggest that the sugar content may be linked to a specific trait that is present in the fruiting $(\mathrm{F})$ cultivars investigated or may have been indirectly selected during breeding programs. We also found that interspecific hybridization between Japanese apricot (P. mume) and apricot (P. armeniaca) may affect both the contents and compositions of sugars and organic acids (Fig. 1AD), which is consistent with the findings of Kakiuchi et al. (1985). Interspecific hybridization is considered as an important event for increasing genetic and phenotypic diversity, which can lead plants to adapt to a wide range of environments and to introduce useful agronomic traits (Rodionov et al., 2019). Our study also indicated that interspecific hybridization could be utilized to increase phenotypic diversity and engineer fruit traits in Japanese apricot.

One of the main objectives of the present study was to characterize the fruit aroma across a range of Japanese apricot cultivars as this determines the quality of processed products such as liquors and syrups (Tokitomo et al., 2005; Oe et al., 2012). The application of PCA to the amounts and compositions of volatile compounds identified hexyl hexanoate, butyl hexanoate, and gamma-decalactone as candidate compounds likely responsible for phenotypic diversity in the fruit aroma trait of Japanese apricot, all of which were mainly detected in the fruiting (F) cultivars, which had strong aroma intensities in the sensory evaluation (Fig. 4). Moreover, the proportion of gammadecalactone showed the highest correlation with the sensory aroma intensity $(r=0.72$, Fig. 2 ; Supplemental Table S5). Gamma-decalactone confers a peach-like aroma in many fruits, such as peach and strawberry (Fragaria $\times$ ananassa) (Sánchez-Sevilla et al., 2014; Peng et al., 2020), and has also been identified as a key volatile compound that is responsible for the favorable sweet aroma of Japanese apricot fruit and the processed products they are used in (Tokitomo et al., 2005; Oe et al., 2012). In strawberry, genetic mapping combined with RNA sequencing identified the fatty acid desaturase FaFADl as the gene controlling the gammadecalactone content of the ripe fruit (Sánchez-Sevilla et al., 2014). Since the content and composition of gamma-decalactone showed wide diversity in the Japanese apricot cultivars examined (Fig. 4C), a genome-wide association study could be performed to identify candidate genomic loci to allow the development of a molecular marker for efficient breeding. Hexyl hexanoate and butyl hexanoate, which confer apple-like and green-like odors, respectively (Mehinagic et al., 2006), were also shown to be positively correlated with the sensory fruit aroma intensity in the Japanese apricot cultivars examined. These volatiles have previously been identified as being responsible for overall fruit aroma in apple (Malus domestica) (Mehinagic et al., 2006), but their role in Japanese apricot fruit has not been shown. In this study, we observed that fruiting (F) cultivars with strong aroma intensities, such as 'Joshuhaku' and 'Suiko' were shown to have lactones and esters in a higher proportion, but a similar trend was not observed in 'Shirokaga'. Therefore, since fruit aroma is considered to be determined by not only the quantities of given compounds but also their compositions and the presence of specific compounds, further investigation will be needed to determine the volatile compound profile for Japanese apricot cultivars. The presence or composition of specific compounds should be taken into account in investigating cultivar-specific aroma profile. Moreover, the effect of fruit aroma profile on processed products needs to be investigated in relation to cultivar difference, since fruit aroma is involved in the quality of liqueurs (Tokitomo et al., 2005; Oe et al., 2012), syrups (Oe et al., 2018), and pickles (Ishida, 2001).

The cultivation of Japanese apricot in Japan was originally undertaken for ornamental purposes, followed by cultivar differentiation to produce a number of subpopulations, such as fruiting (F), fruiting-small (FS), and ornamental (O) (Numaguchi et al., 2020). Although the two major cultivars, 'Nanko' and 'Shirokaga', together accounted for about $46 \%$ of the total cultivation area of fruit production in 2018 , minor cultivars are still cultivated locally (Ministry of Agriculture, Forestry and Fisheries, 2021). Our investigation revealed that 'Joshuhaku' appears to have desirable fruit traits for use, including a large fruit size, high sensory aroma intensity, and high contents of citric acid and favorable volatile compounds. Indeed, 'Joshuhaku' was used as a breeding ancestor in 'Suiko', which has a characteristic fruit aroma (Yaegaki et al., 2014). Thus, minor cultivars may be promising material for production, as well as future breeding programs.

In conclusion, our comprehensive analysis of fruit traits revealed substantial phenotypic diversity among Japanese apricot cultivars. In particular, the fruiting $(\mathrm{F})$ cultivars, which mainly include major cultivars, were shown to have higher contents of sugar and favorable volatile compounds, such as gamma-decalactone and hexanoate esters. Moreover, the results indicate that interspecific hybridization has large effects on fruit trait diversity. Thus, it appears that cultivar difference and interspecific hybridization is associated with diverse phenotypic variation in Japanese apricot. These observations can be utilized for breeding new Japanese apricot cultivars.

\section{Acknowledgements}

We deeply thank Mr. Masanobu Ikeno, Japanese apricot producer in Joyo city, Kyoto prefecture, for providing fruit materials. We are also grateful to researchers at 
the Industrial Technology Center of Wakayama prefecture for analyzing volatile compounds.

\section{Literature Cited}

Baltussen, H. A., F. David, P. J. F. Sandra, J. G. M. Janssen and C. A. M. G. Cramers. 1999. Equilibrium sorptive enrichment on poly (dimethylsiloxane) particles for trace analysis of volatile compounds in gaseous samples. Anal. Chem. 71: 5193-5198.

Hayashi, K., K. Shimazu, H. Yaegaki, M. Yamaguchi, H. Iketani and T. Yamamoto. 2008. Genetic diversity in fruiting and flower-ornamental Japanese apricot (Prunus mume) germplasms assessed by SSR markers. Breed. Sci. 58: 401410.

Horiuchi, S. 1996. Chugoku no hanaume no bunrui. p. 75-89. In: S. Horiuchi (ed.). Nihonnoume Sekainoume (In Japanese). Yokendo, Tokyo.

Ishida, M. 2001. Volatile compounds of umeboshi. The Koryo 211: 139-156 (In Japanese with English abstract).

Kakiuchi, N., K. Ishikawa, S. Moriguchi, H. Kyotani and M. Yoshida. 1985. Changes in organic acid and free amino acid compositions of "Mume" fruits relation to variety and harvest maturity. Nippon Shokihin Kogyo Gakkaishi 32: 669676 (In Japanese with English abstract).

Mehinagic, E., G. Royer, R. Symoneaux, F. Jourjon and C. Prost. 2006. Characterization of odor-active volatiles in apples: influence of cultivars and maturity stage. J. Agric. Food Chem. 54: 2678-2687.

Ministry of Agriculture, Forestry and Fisheries. 2020. Sakkyou chousa (kazyu). <https://www.maff.go.jp/j/tokei/kouhyou/ sakumotu/sakkyou_kazyu/index.html $>$.

Ministry of Agriculture, Forestry and Fisheries. 2021. Tokusan kaju seisan doutai tou chousa. <https:/www.maff.go.jp/j/ tokei/kouhyou/tokusan_kazyu/index.html>.

Morimoto, T., Y. Kitamura, K. Numaguchi, T. Akagi and R. Tao. 2019. Characterization of post-mating interspecific crosscompatibility in Prunus (Rosaceae). Sci. Hortic. 246: 693699.

Negoro, K., K. Hayashi, K. Iwamoto and T. Oe. 2007. Breeding of self-compatible Japanese apricot with rich in $\beta$-carotene by crossing 'Nanko' and 'Jizo'. Hort. Res. (Japan) 6 (Suppl. 2): 469 (In Japanese).

Numaguchi, K., T. Akagi, Y. Kitamura, R. Ishikawa and T. Ishii. 2020. Interspecific introgression and natural selection in the evolution of Japanese apricot (Prunus mume). Plant J. 104: $1551-1567$.

Numaguchi, K., S. Ishio, Y. Kitamura, K. Nakamura, R. Ishikawa and T. Ishii. 2019. Microsatellite marker development and population structure analysis in Japanese apricot (Prunus mume Sieb. et Zucc.). Hort. J. 88: 222-231.

Oe, T., N. Sakurai, T. Yamasaki, Y. Okui, N. Ishihara, M.
Okamuro and M. Hosohira. 2012. Effect on the ripening condition in the Japanese apricot (Prunus mume) 'Nanko' fruit on the aroma and bitter components of its processed liqueur. Hort. Res. (Japan) 11: 273-279 (In Japanese with English abstract).

Oe, T., Y. Tsuchida, M. Okamuro and A. Yukumori. 2018. Effect of the harvesting time and force ripening condition in Japanese apricot (Prunus mume Sieb. et Xucc.) 'Suiko' on the quality of fruit and processed ume liqueur and syrup. Bull. Wakayama Pref. Exp. Sta. Agric. Forestry and Fisheries 6: 61-71 (In Japanese).

Peng, B., J. Xu, X. Cai, B. Zhang, M. Yu and R. Ma. 2020. Different roles of the five alcohol acyltransferases in peach fruit aroma development. J. Amer. Soc. Hort. Sci. 145: 374-381.

Rodionov, A. V., A. V. Amosova, E. A. Belyakov, P. M. Zhurbenko, Y. V. Mikhailova, E. O. Punina, V. S. Shneyer, I. G. Loskutov and O. V. Muravenko. 2019. Genetic consequences of interspecific hybridization, its role in speciation and phenotypic diversity of plants. Russian J. Genet. 55: 278-294.

Sánchez-Sevilla, J. F., E. Cruz-Rus, V. Valpuesta, M. A. Botella and I. Amaya. 2014. Deciphering gamma-decalactone biosynthesis in strawberry fruit using a combination of genetic mapping, RNA-Seq and eQTL analyses. BMC genomics 15: 1-15.

Tokitomo, Y., S. Mukawa and Y. Endo. 2005. Flavor of ume liquor prepared from small ume fruit (Prunus mume Sieb. et Zucc.). J. Jpn. Soc. Food Sci. Tech. (Japan) 52: 330-336 (In Japanese with English abstract).

Yaegaki, H., T. Haji, Y. Nakamura, M. Miyake, K. Nishimura, H. Kyotani and M. Yamaguchi. 2003. Variety and yearly variations of fruit and endocarp weights and their ratio in Japanese apricot (Prunus mume Sieb. et Zucc.) cultivars. J. Japan. Soc. Hort. Sci. 72: 546-550 (In Japanese with English abstract).

Yaegaki, H., M. Yamaguchi, T. Haji, Y. Suesada, Y. Nakamura, H. Kyotani, K. Nishimura, M. Miyake, E. Adachi, T. Kozono, H. Fukuda, T. Kihara, K. Suzuki and M. Uchida. 2014. New Japanese apricot cultivar 'Suiko'. Bull. NARO. Inst. Fruit Tree Sci. 17: 1-11 (In Japanese with English abstract).

Yamaguchi, M., H. Kyotani, M. Yoshida, T. Haji, K. Nishimura, Y. Nakamura, M. Miyake, H. Yaegaki, T. Nishida, N. Kakiuchi, K. Tanaka, A. Omiya, Y. Ishikawa, T. Kosono, T. Kihara, K. Suzuki, H. Fukuda and T. Asakura. 2002. New Japanese apricot cultivar 'Hachiro'. Bull. Natl. Inst. Fruit Tree Sci. 1: 35-46 (In Japanese with English abstract).

Yoshida, M. 1996a. Ume no kigen to rekishi. p. 16-21. In: S. Horiuchi (ed.). Nihonnoume Sekainoume (In Japanese). Yokendo, Tokyo.

Yoshida, M. 1996b. Ume no hinshu keitou bunrui. p. 29-45. In: S. Horiuchi (ed.). Nihonnoume Sekainoume (In Japanese). Yokendo, Tokyo. 